\title{
Feasibility of Using BAAM for Mold Inserts for the Precast Concrete Industry
}

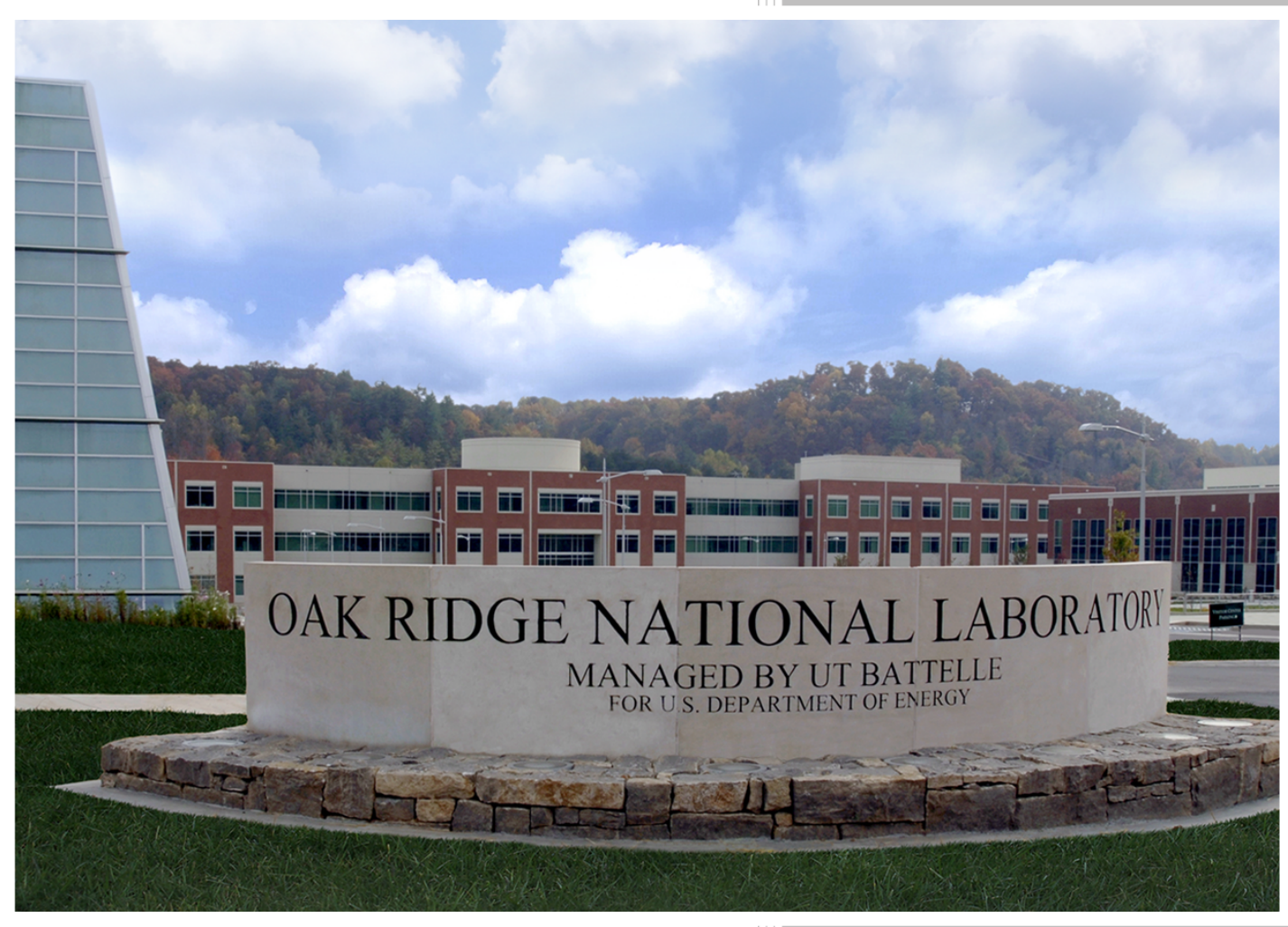

Lonnie J. Love

Brian K. Post

Alex C. Roschli

Phillip C. Chesser

Diana E. Hun

September 2019

\section{Approved for Public Release.} Distribution is Unlimited. 


\title{
DOCUMENT AVAILABILITY
}

Reports produced after January 1, 1996, are generally available free via US Department of Energy (DOE) SciTech Connect.

Website http://www.osti.gov/scitech/

Reports produced before January 1, 1996, may be purchased by members of the public from the following source:

\author{
National Technical Information Service \\ 5285 Port Royal Road \\ Springfield, VA 22161 \\ Telephone 703-605-6000 (1-800-553-6847) \\ TDD 703-487-4639 \\ Fax 703-605-6900 \\ E-mail info@ntis.gov \\ Website http://www.ntis.gov/help/ordermethods.aspx
}

Reports are available to DOE employees, DOE contractors, Energy Technology Data Exchange representatives, and International Nuclear Information System representatives from the following source:

Office of Scientific and Technical Information

PO Box 62

Oak Ridge, TN 37831

Telephone 865-576-8401

Fax 865-576-5728

E-mail reports@osti.gov

Website http://www.osti.gov/contact.html

This report was prepared as an account of work sponsored by an agency of the United States Government. Neither the United States Government nor any agency thereof, nor any of their employees, makes any warranty, express or implied, or assumes any legal liability or responsibility for the accuracy, completeness, or usefulness of any information, apparatus, product, or process disclosed, or represents that its use would not infringe privately owned rights. Reference herein to any specific commercial product, process, or service by trade name, trademark, manufacturer, or otherwise, does not necessarily constitute or imply its endorsement, recommendation, or favoring by the United States Government or any agency thereof. The views and opinions of authors expressed herein do not necessarily state or reflect those of the United States Government or any agency thereof. 
Energy \& Transportation Science Division Advanced Manufacturing Office

Feasibility of Using BAAM for Mold Inserts for the Precast Concrete Industry

\author{
Authors \\ Lonnie J. Love \\ Brian K. Post \\ Alex C. Roschli \\ Phillip C. Chesser \\ Diana E. Hun \\ Steve Brock \\ Nathan Brooks
}

Date Published:

September 2019

\author{
Prepared by \\ OAK RIDGE NATIONAL LABORATORY \\ Oak Ridge, Tennessee 37831-6283 \\ managed by \\ UT-BATTELLE, LLC \\ for the \\ US DEPARTMENT OF ENERGY \\ under contract DE-AC05-00OR22725
}

Approved For Public Release 



\section{CONTENTS}

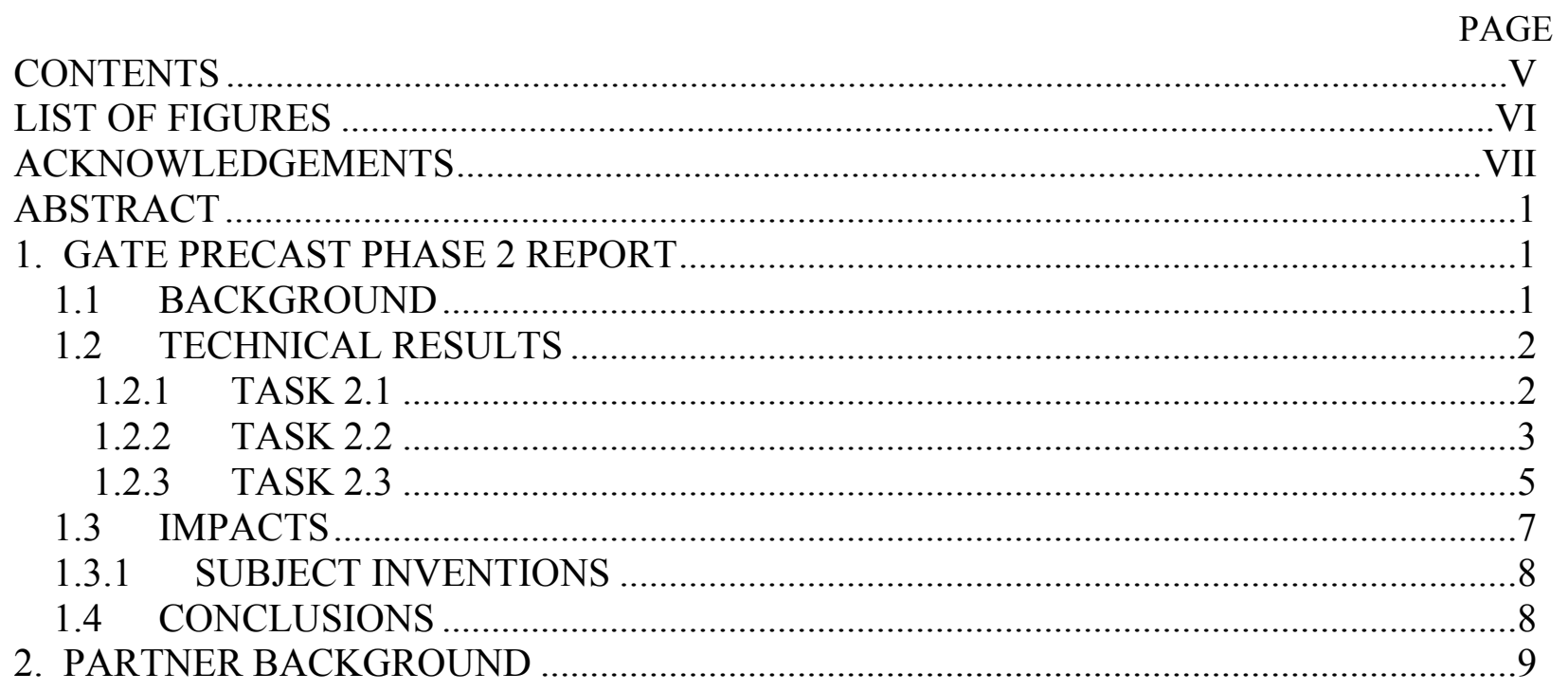




\section{LIST OF FIGURES}

Figure 1. Side view of final part from Phase 1

Figure 2. An oversized mold that doesn't fit within the build volume of the 8x20 BAAM system.

Figure 3. Two of the four pieces after printing to be machined and assembled into a large mold.

Figure 4. A closeup of a sharp corner after machining one piece to be assembled into a large mold...

Figure 5. A fully assembled mold of four individual pieces ................................................4

Figure 6: A mold surface with large flat surfaces on each end .............................................5

Figure 7. G-Code showing the back and forth pathing needed for a solid top surface .................5 


\section{ACKNOWLEDGEMENTS}

This CRADA NFE-17-06874 was conducted as a Technical Collaboration project within the Oak Ridge National Laboratory (ORNL) Manufacturing Demonstration Facility (MDF) sponsored by the US Department of Energy Advanced Manufacturing Office (CPS Agreement Number 24764). Opportunities for MDF technical collaborations are listed in the announcement "Manufacturing Demonstration Facility Technology Collaborations for US Manufacturers in Advanced Manufacturing and Materials Technologies" posted at http://web.ornl.gov/sci/manufacturing/docs/FBO-ORNL-MDF-2013-2.pdf. The goal of technical collaborations is to engage industry partners to participate in short-term, collaborative projects within the Manufacturing Demonstration Facility (MDF) to assess applicability and of new energy efficient manufacturing technologies. Research sponsored by the U.S. Department of Energy, Office of Energy Efficiency and Renewable Energy, Advanced Manufacturing Office, under contract DE-AC05-00OR22725 with UT-Battelle, LLC. 


\begin{abstract}
Oak Ridge National Laboratory worked with Gate Precast to demonstrate the viability of using carbon fiber reinforced acrylonitrile butadiene styrene (ABS) plastic and the Big Area Additive Manufacturing (BAAM) technology to rapidly manufacture molds for the precast concrete industry. This Phase 2 project focused on developing more complex molds that will be used in production.
\end{abstract}

\title{
1. GATE PRECAST PHASE 2 REPORT
}

This Phase 2 technical collaboration project (MDF-TC-2017-127) began on September 18, 2017. Gate Precast, the collaboration partner, is a medium sized business. The results of the second phase of this project included successful printing of the remaining molds, successful use of the molds by Gate Precast to cast concrete panels, and the beginning of the installation of the precast panels on the structure in Brooklyn.

\subsection{BACKGROUND}

The conventional methodology to manufacture precast concrete is based on manufacturing wooden molds manually. For complex mold designs, the process is slow, expensive and the high-skilled workforce has shrunk. Current mold manufacturing techniques involve assembling mostly plywood sheets and finishing their surfaces with fiberglass reinforced coatings. The availability of skilled craftsmen who can do this task has been continuously declining; therefore, precasters have not been able to keep up with technological advances, such as the ability to design complex geometries through Building Information Modeling (BIM). The precast industry needs a new mold manufacturing process that takes advantage of the latest technological advances to remain competitive in the construction market. Additive manufacturing has the potential to greatly improve the efficiency and cost effectiveness of this process.

ORNL and the Precast/Prestressed Concrete Institute (PCI) have been collaborating on advancing precast construction since 2015. In support of this program, Gate Precast, a PCI member, volunteered an upcoming project, which is part of the Domino Sugar Site A redevelopment in Brooklyn, NY, for use as a pilot technology verification and case study of a new mold manufacturing process. The new 42-story building has a very complex façade in which deep precast panels will serve as solar shading devices. The façade requires about 70 different molds that are ideal to evaluate the proposed manufacturing method versus business as usual. ORNL and Gate Precast planned to design, manufacture and evaluate 3D printed mold prototypes, and then start actual production of molds and precast façade components.

The first phase of this technical collaboration explored the use of carbon fiber reinforced ABS as a material for precast molds. Gate Precast was able to use the carbon fiber reinforced ABS mold to produce mockup concrete parts that were representative of those that would be used in 
the façade of the new building (Figure 1). The results of the Phase 1 activities were sufficient to move forward to the second phase that would produce the molds that would be used to cast the actual concrete parts.

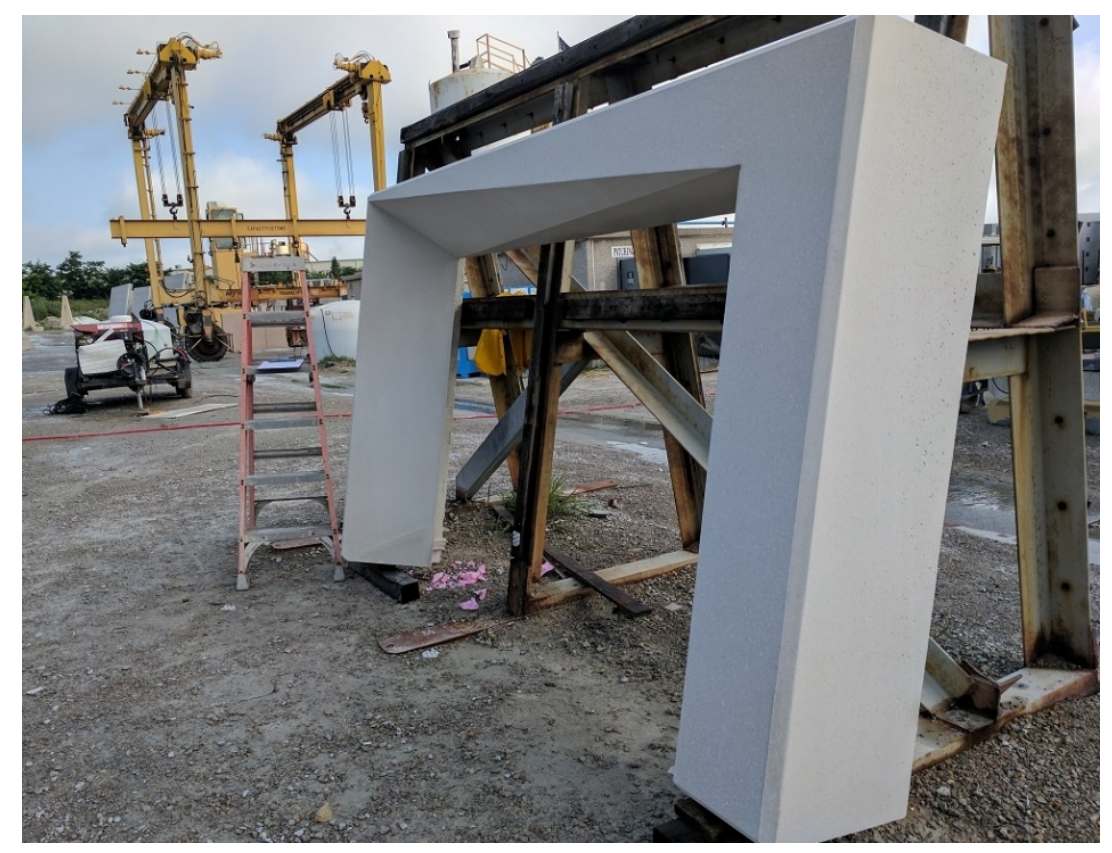

Figure 1. Precast mockup that was produced using a 3D printed mold from Phase 1

The main goal of this R\&D effort is to determine, on behalf of the entire domestic precast industry, whether 3D printed mold manufacturing is, or can become, cost-effective for this industry. To this end, ORNL and Gate Precast will gather data on the mold manufacturing process (e.g., 3D printed materials, optimization of mold designs, production time), and mold performance (e.g., durability, quality of concrete surface finish). This information will be compared to data from traditional mold manufacturing techniques. This assessment will de-risk an advanced manufacturing technique that has the potential to be extremely beneficial to the precast industry as it could reduce the manufacturing time of complex molds by about $50 \%$.

\subsection{TECHNICAL RESULTS}

In this Phase 2 project, Gate provided ORNL with designs for more geometrically complex molds, including oversized molds (Task 2.1). ORNL printed and machined these molds (Task 2.2). Gate inspected the molds, used them to manufacture concrete panels that are being added to the façade of the high rise building in Brooklyn, NY, and provided feedback to ORNL on their performance (Task 2.3).

\subsubsection{Task 2.1}

The molds produced in Phase 1 were basic rectangular molds with mostly vertical walls. The geometry challenges were minimal, but enough to verify the concept. In Phase 2, the geometry of the molds got more complex, which required more design effort for successful manufacturing. The biggest challenge was handling the oversized molds. These molds didn't fit 
on the BAAM system and so could not be printed in one piece (Figure 2).

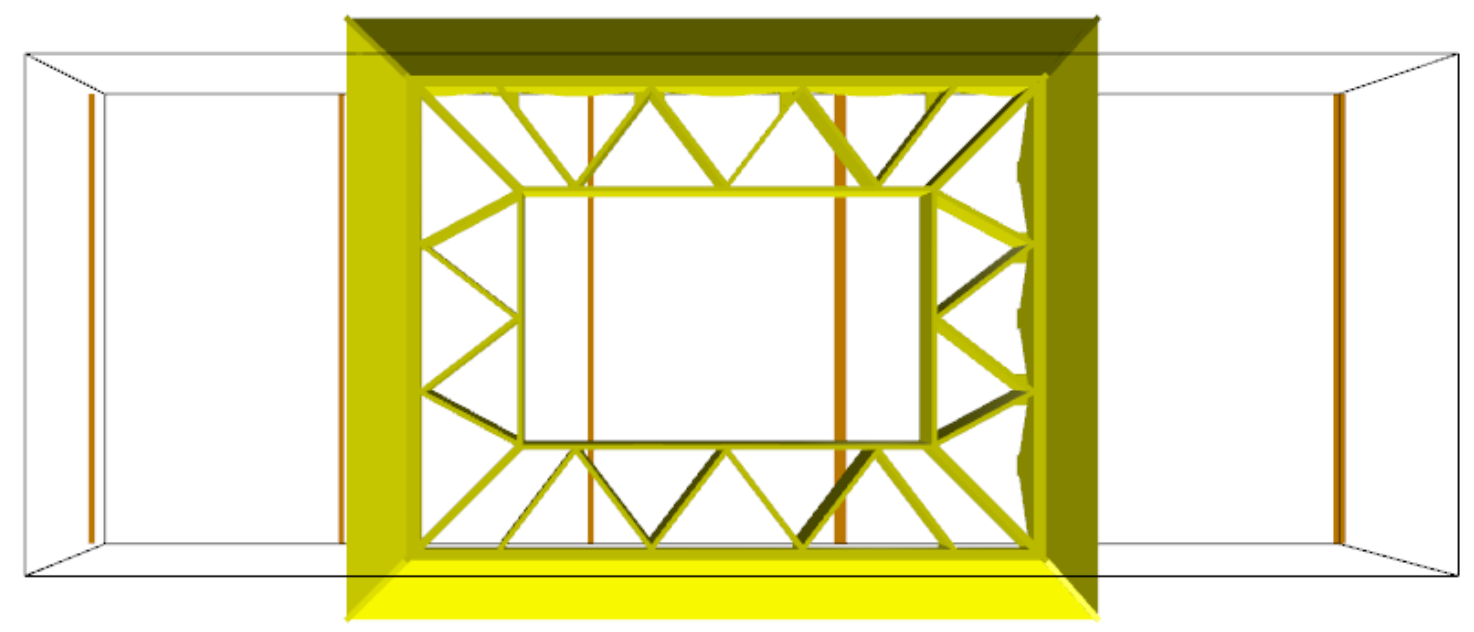

Figure 2. An oversized mold that doesn't fit within the build volume of the 8x20 BAAM system

\subsubsection{Task 2.2}

To remedy the issue of oversized molds, the large molds had to be broken into smaller pieces that could be individually machined and then reassembled into one large complete mold. The challenge was in how to build the mold pieces so that they would go back together seamlessly. If the pieces didn't perfectly line up, a seam would be present on the finished concrete piece. The solution was to divide the mold into four pieces, oversize each one, and then machine the individual pieces to tight tolerances with sharp corners that could be fit back together as one mold (Figure 3, Figure 4, and Figure 5).

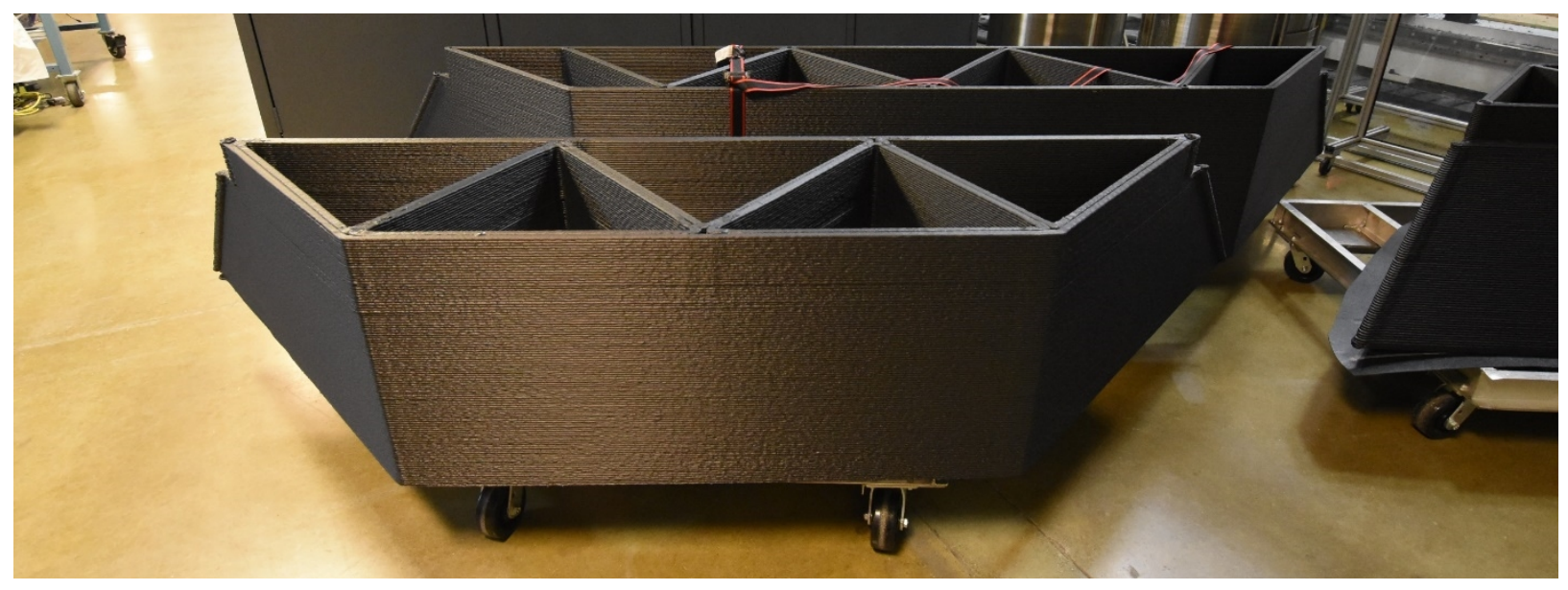

Figure 3. Two of the four pieces after printing to be machined and assembled into a large mold. 


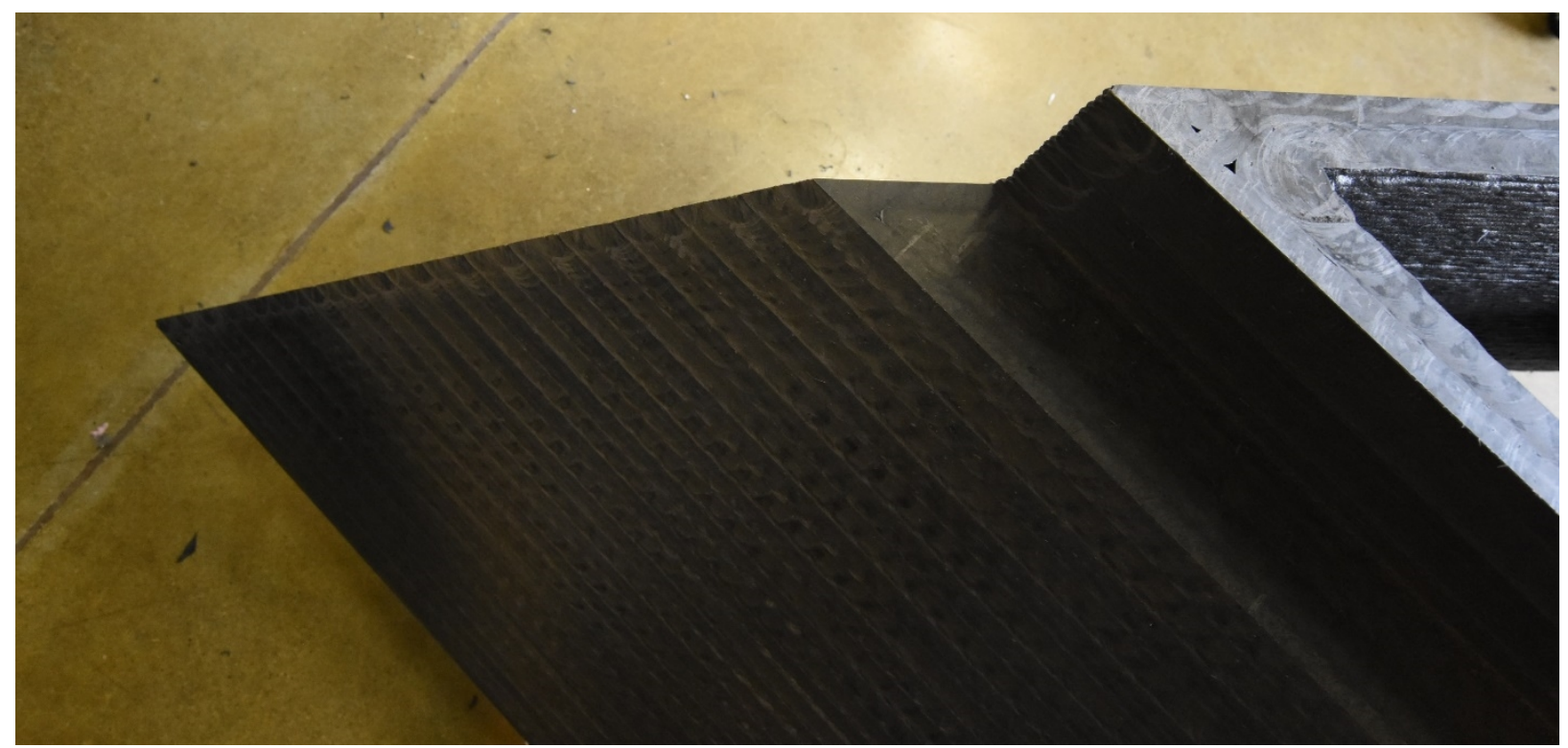

Figure 4. A closeup of a sharp corner after machining one piece to be assembled into a large mold

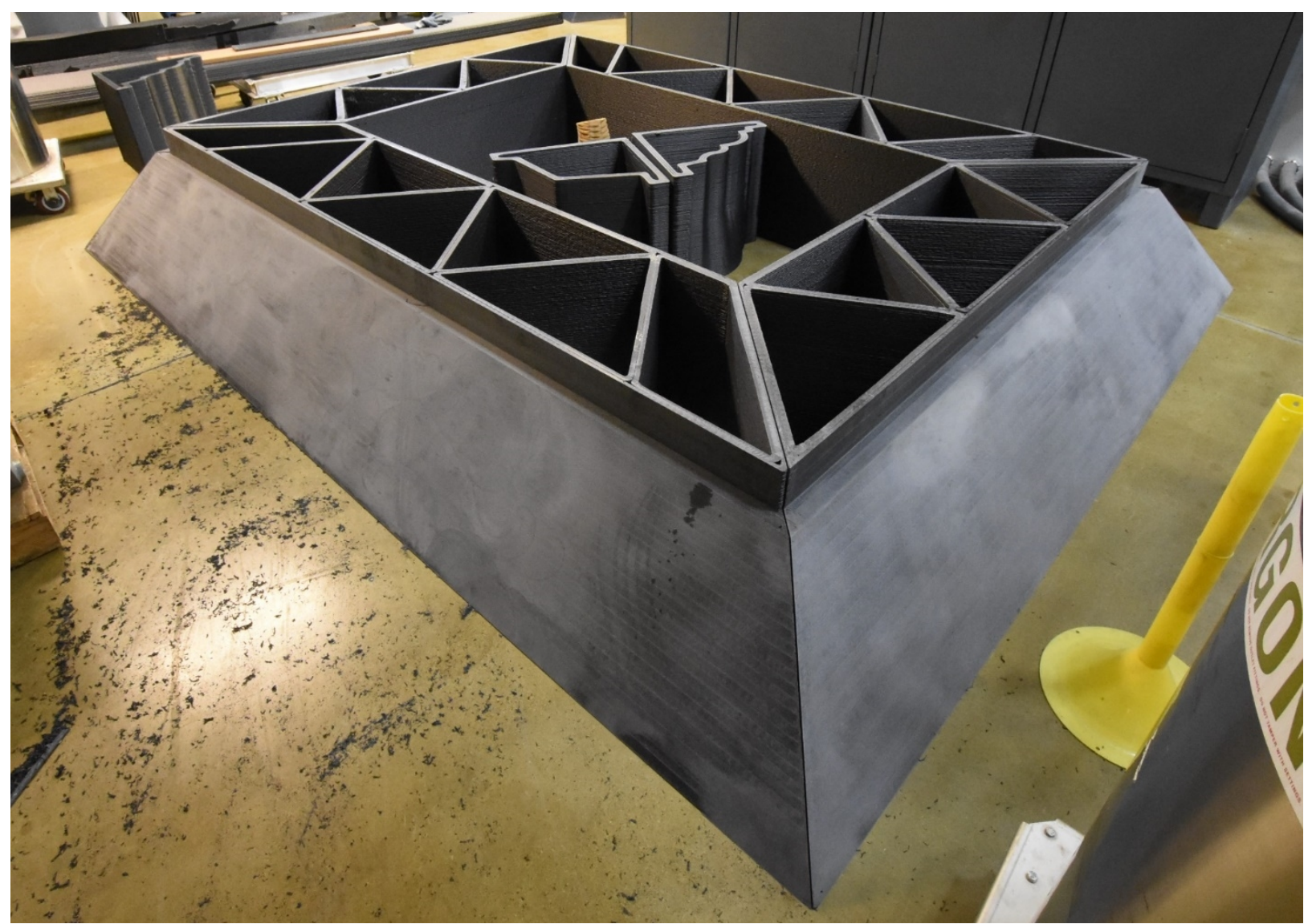

Figure 5. A fully assembled mold of four individual pieces 
Once the designs were finalized, slicing was needed to prepare the molds for manufacturing. Molds with large flat surfaces, like that of Figure 6, produced a final part with poor surface quality when the mold was printed the normal way with a grid-based infill pattern. This is because the infill patterns left voids in the corners that were exposed during machining. The solution to this was a slight redesign of the flat surface so that the bead path was forced into a back and forth motion that could be greatly overfilled (Figure 7). To make the redesign work, new code had to be developed for the ORNL Slicer to prevent the software from optimizing the print time of the part by reverting to the old pathing method. This new approach is called polygon unoptimization.

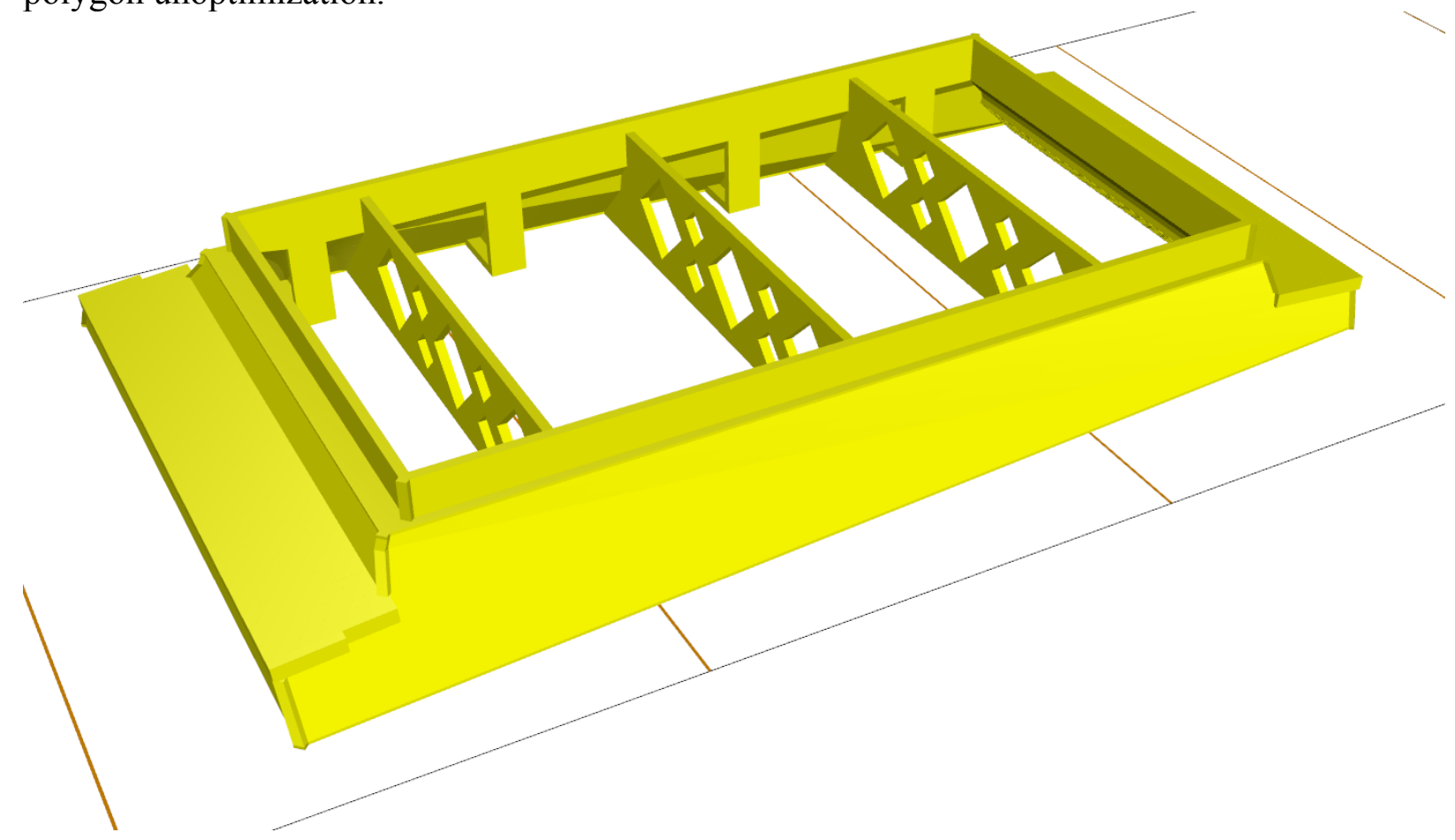

Figure 6: A mold surface with large flat surfaces on each end

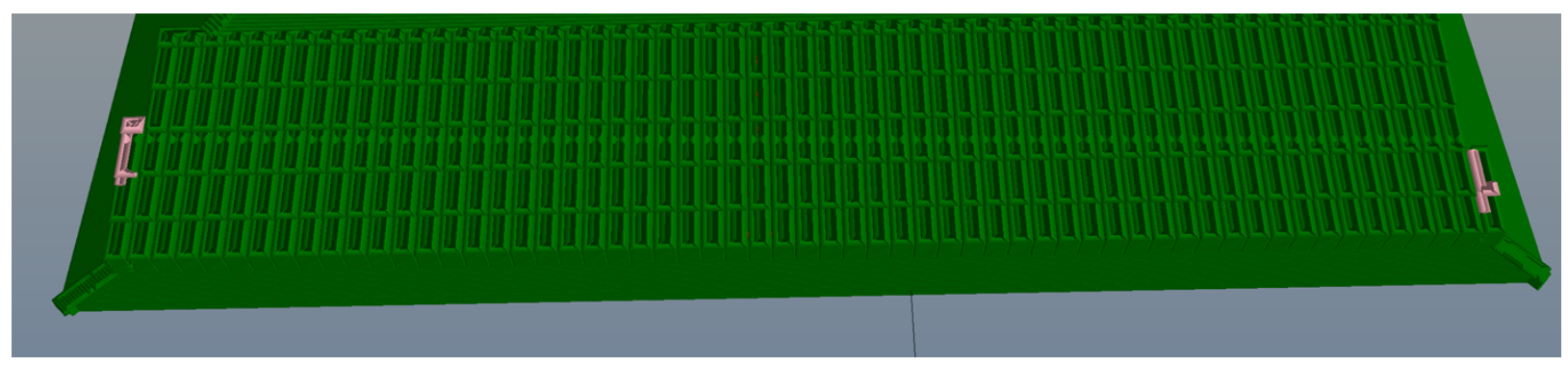

Figure 7. G-Code showing the back and forth pathing needed for a solid top surface 

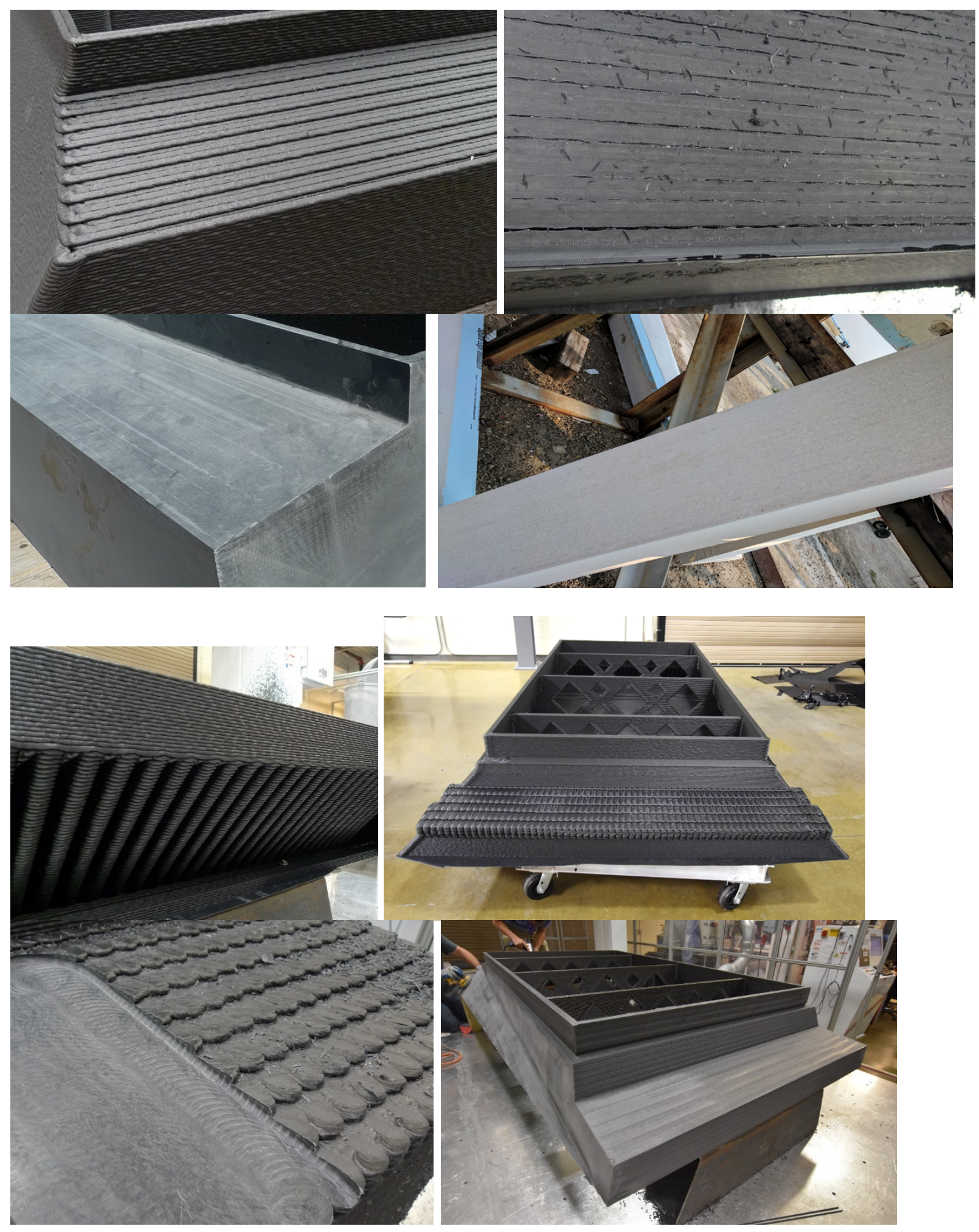

\subsubsection{Task 2.3}


All mold production by ORNL is complete and Gate finished using these molds to produce the precast panels in their plant that is located in Winchester, KY. Figure 8 shows these panels at the construction site while they wait to be installed.

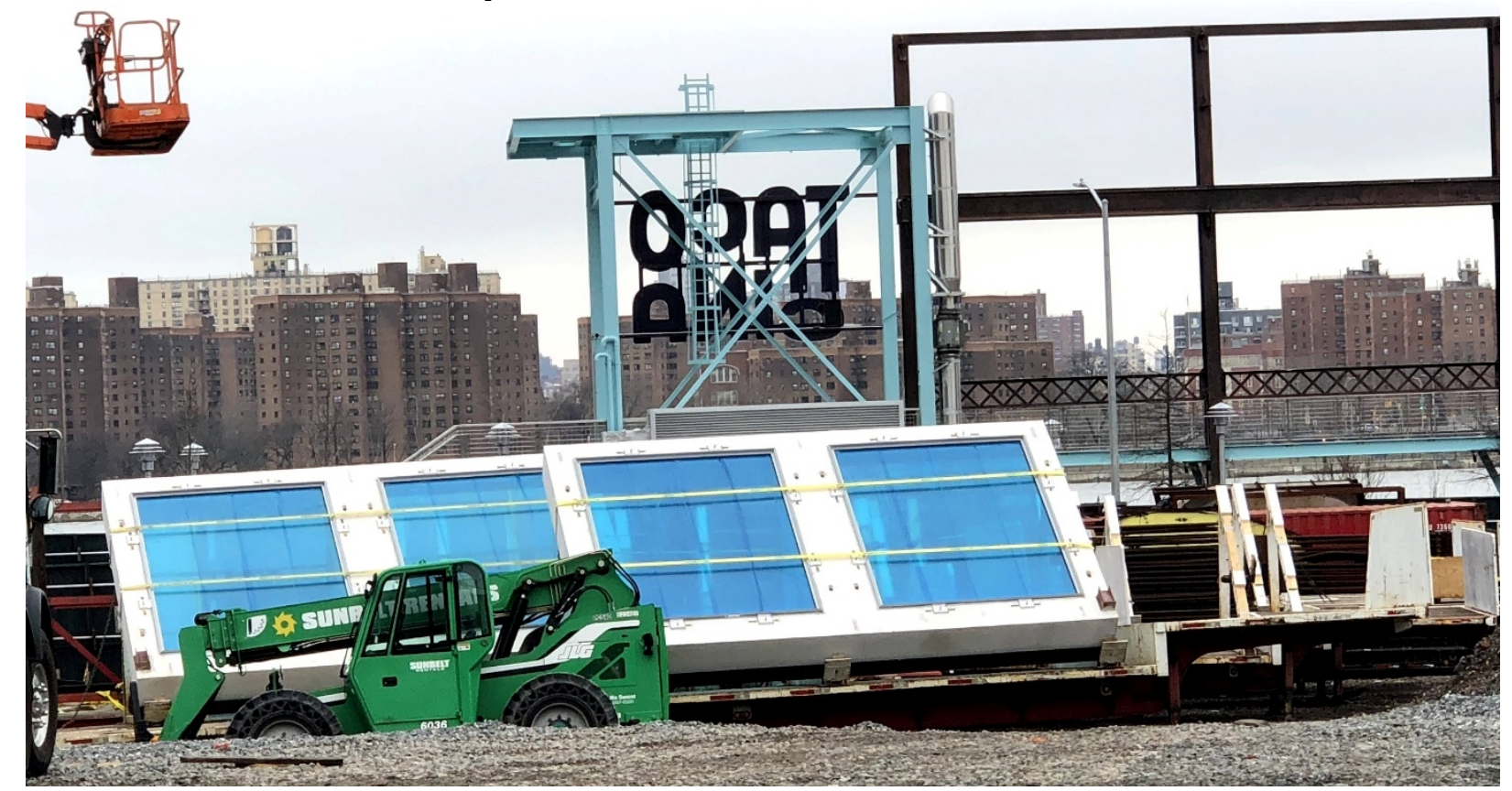

Figure 8. A truck full on concrete panels with windows inserted, ready for attaching to the building

Construction of the high-rise is still under way in Brooklyn. Most of the precast panels have been installed. Figure 9 shows the façade with panels part way up the exterior. The durability of the molds has proven to be more than adequate. Gate Precast has reported upwards of 200 "pulls" per mold without major degradation of the mold surface, which is about 10 times more than the traditional method. 


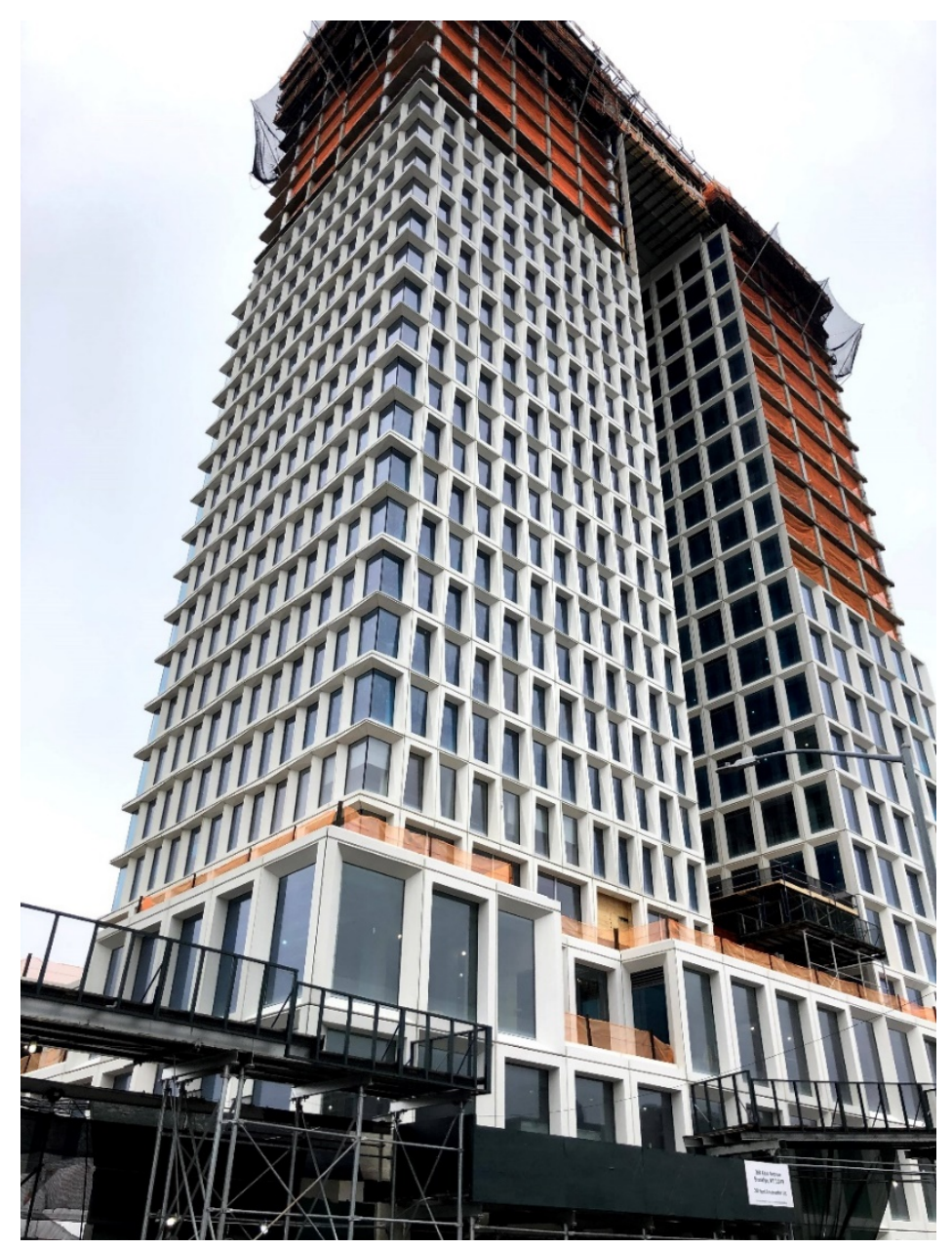

Figure 9. Concrete panels on the façade of the new Domino Sugar Building

\subsection{IMPACTS}

Additive manufacturing of the concrete molds had a big impact on the project and the precast industry. With additive manufacturing, molds can be made faster and can be made offsite to not disrupt production. The additively manufactured molds have crisper edges and vibrate better on the vibration tables allowing the concrete to flow better through the mold and minimize bug holes. Additive is a natural fit for complex molds where traditional wood molds would require numerous man hours to construct, but also for basic molds where the cost of steel molds isn't justifiable.

We were able to show that an additive mold can be used more than 200 times with minimal degradation. Traditional wooden molds only last about 20 pours before the surface has to be refinished. This doesn't mean remaking the whole mold, but it does take time and cost money to resurface. The initial cost of a BAAM mold is about $3 \mathrm{x}$ of a wood mold but gets significantly more pours and doesn't need to be refinished. Table 1 shows a cost comparison for wood and BAAM molds. 
Table 1: Cost comparison for traditional manufacturing versus 3D printing with BAAM

\begin{tabular}{|l|l|l|}
\hline & Traditional Method & BAAM \\
\hline Cost per Mold & $\$ 3000$ & $\$ 9000$ \\
\hline Pours per Mold & 20 & 200 \\
\hline Cost per Pour & $\$ 150$ & $\$ 45$ \\
\hline
\end{tabular}

\subsubsection{SUBJECT INVENTIONS}

No patents or inventions were the result of this effort.

\subsection{CONCLUSIONS}

This project has completed successfully. ORNL was able to 3D print all the needed molds for Gate Precast to finish the construction of the new Domino Sugar Building façade and prove the feasibility of additive manufacturing for precast concrete. Using BAAM, we were able to demonstrate a significant reduction in cost per mold for production. Future research will involve using lower cost materials, such as glass fiber reinforced ABS or PLA that is reinforced with wood flour, to bring the cost down further. ORNL has also helped to transition this technology to industry partner AES who is commercializing the technology for American businesses. 


\section{PARTNER BACKGROUND}

In 1980, Gate Petroleum gave rise to Gate Construction Materials Group when it began to acquire non-petroleum businesses. Thirty-six years later, the group is one of the nation's largest producers of architectural precast concrete, pre-stressed hollow core slabs, transportation/infrastructure and marine components, operating eight manufacturing facilities located in North Carolina, Alabama, Kentucky, Tennessee, two in Florida and two in Texas. At these state-of-the art plants, architectural and structural concrete are designed, manufactured, delivered and installed to customers in over two-thirds of the United States.

Gate is committed to the research and development of innovative product lines that expand the versatility of precast and its vital role in the construction industry. Gate recognizes its responsibility to respect the environment, community and the health and safety of its employees.

Gate's high standard of service and business ethics, coupled with a quality product instills consumer confidence, which ultimately benefits the community as a whole. We are committed to construction and operational practices that respect the environment.
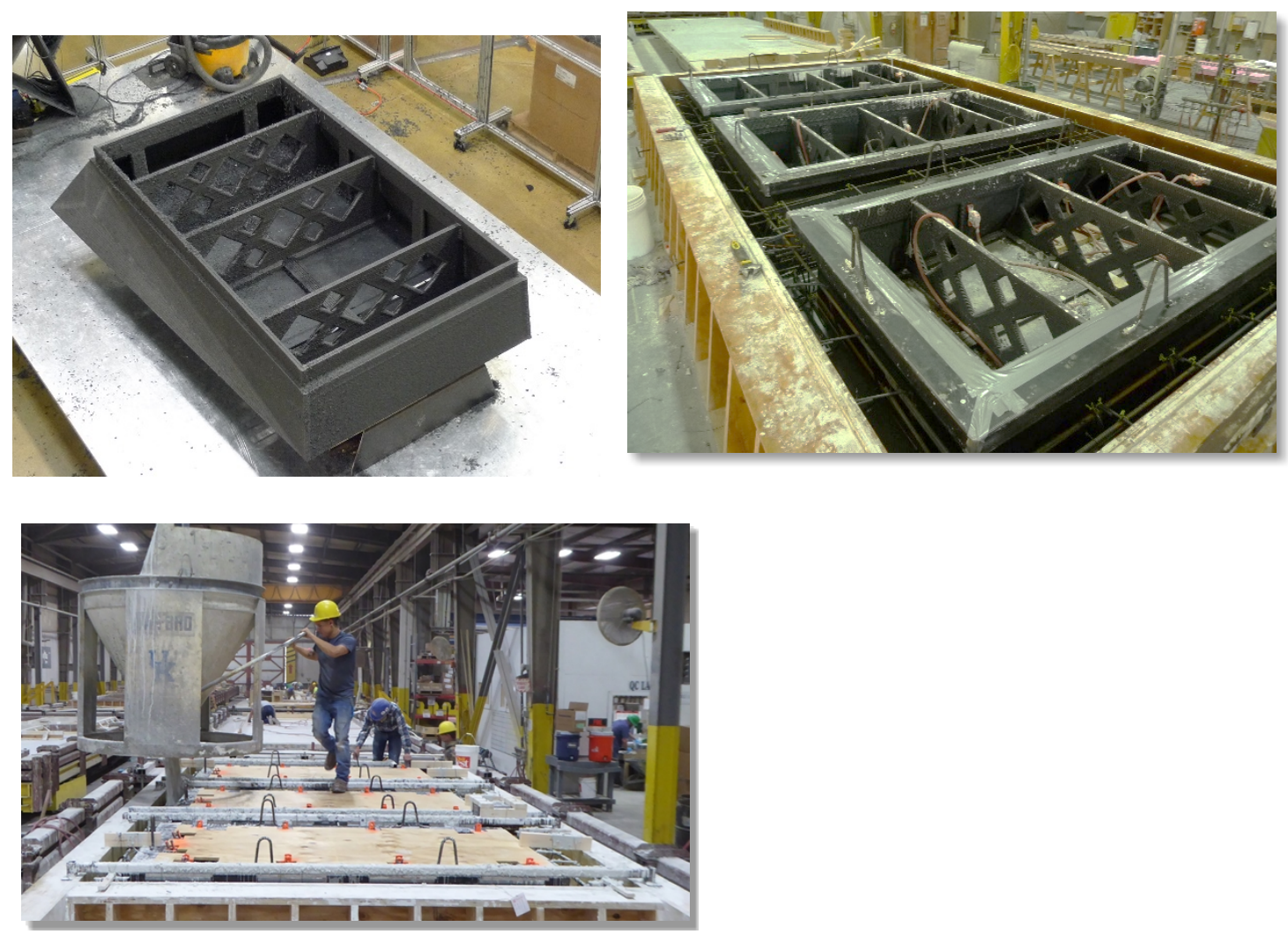


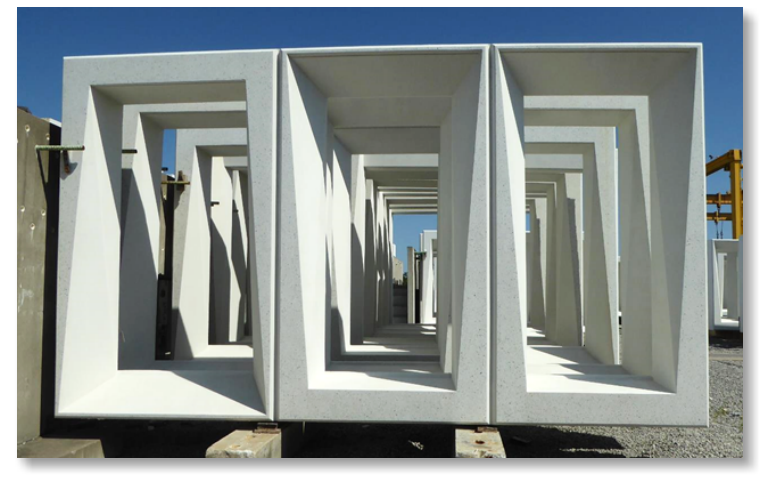

